\title{
UTILIZATION OF SPACEBORNE C-BAND SAR DATA FOR ANALYSIS OF FLOOD IMPACT ON AGRICULTURE AND ITS MANAGEMENT
}

\author{
Akshar Tripathi ${ }^{1 *}$ and Reet Kamal Tiwari ${ }^{1}$ \\ Department of Civil Engineering, Indian Institute of Technology Ropar \\ Rupnagar, Punjab, India \\ kshrtripathi@gmail.com, reetkamal@iitrpr.ac.in,
}

Commission III, WG III/10

KEY WORDS: SAR Interferometry, Coherence, Flood inundation, interferogram, Flood management

\begin{abstract}
:
North India, since time immemorial remained the cradle of agricultural development. Every year during the monsoons, there is a high upsurge in the river Rapti. This leads to heavy flooding in the area and takes a toll on life and property besides submerging acres of precious agricultural land. Till now, such floods have been mapped using satellite data from optical sensors, but in monsoons due to cloud cover the task becomes difficult. Spaceborne SAR (Synthetic Aperture RADAR) data solves this problem by offering all-weather availability. This study aims to utilize the potential of C-band dual PolSAR data from Sentinel-1A for flood mapping and analysis of its impact on agriculture along with suggesting mitigation measures. Sentinel-1A data of January and September 2018 was taken and pre-processed. Thereafter, an interferogram was prepared and was phase filtered using modified Goldstein phase filter to remove phase distortions and a DEM (Digital Elevation Model) was prepared. The phase maps generated were analyzed for phase variations after removing the topographic phase and it was found that there was very less phase variation from urban and agricultural lands surrounding the river which clearly indicated heavy flooding and submergence of land in water. Using the DEM map generated, hydrological processing was done to delineate flow lines and calculation of catchment area at point of maximum submergence of agricultural land. This was followed by the generation of contours in the area and finally, the flood impact analysis was done by calculating the water volume in watershed during the flood.
\end{abstract}

\section{INTRODUCTION}

SAR or Microwave remote sensing has truly revolutionised the world of remote sensing with its versatile nature and all-weather availability (Abdikan, Sanli, Ustuner, \& Calò, 2016). Like many other areas of study, SAR remote sensing has been highly useful in mapping and analysis of floods (Tripathi \& Kumar, 2017). Floods have been a normal natural calamity for the people living in areas of low elevation (Huete, 2011). And every year, there is a huge loss of life and property which people of these areas face. The reasons for this are miscellaneous, sometimes the rivers swell up due to rains and at other times there is untimely release of water from dams (Confuorto, Plank, Novellino, Tessitore, \& Ramondini, 2016). This results into large scale water logging and submergence of agricultural areas (Dore, Patruno, Pottier, \& Crespi, 2013). This study aims to evaluate the potential of SAR data for the mapping and analysis of flood in the Terai area lying on the foothills of Nepal Himalayas. The study area is Gorakhpur city and adjoining areas. This area being the hub of development activities in eastern Uttar Pradesh is unable to harvest the benefits of government efforts due to yearly floods in the Rapti river and its tributaries (Chen, Masini, Liu, You, \& Lasaponara, 2016). In this study, it was aimed to analyse the flood scenario using C-band SAR data and find out ways to minimise the impact of floods and store the logged water for further usage in dry seasons. Also, it was intended to map and calculate the submerged agricultural land. The Digital Elevation Map (DEM) generated after phase unwrapping was used to generate flow lines using HEC-GEOHMS tool. The flood lines were analysed and thereafter watershed area was delineated. Using this watershed area, flow lines were clipped out lying in it and using that a location at stream junction was chosen which has maximum area of submergence. And using this, the volume of water was calculated to suggest a reservoir to be built at this place of adequate capacity to minimise the impact of flood and provide water for domestic and other purposes.

\section{STUDY AREA AND DATASET}

\subsection{Study Area}

The study area chosen for this study is the city of Gorakhpur in eastern Uttar Pradesh. Located in $26.7588{ }^{\circ} \mathrm{N}$ and $83.3697^{\circ} \mathrm{E}$, the city is located on the banks of river Rapti, adjoining the international border with Nepal. It is the headquarters of Gorakhpur district and Gorakhpur division and has been one of the most flood vulnerable districts of Uttar Pradesh and there has been a considerable increase in the frequency and intensity of floods in the last one-hundred years. Situated in the low lying terai region, accumulated flood waters make the development difficult and cause an increase in diseases and delay in essential relief services to reach in time. Therefore, it was necessary for proper inundation mapping of floods in the region.

\subsection{Datasets}

The datasets chosen was Single Look Complex (SLC) Interferometric pair of C-band SAR data from Sentinel-1 one from the month of January 2018 and the other one from September 2018 with dual polarisation channels of VV and VH 


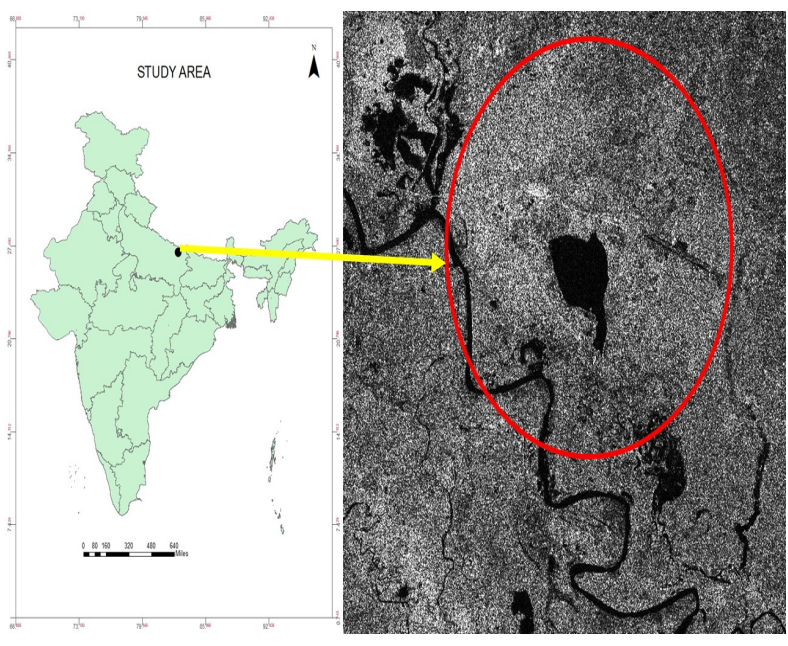

Figure.1. Study area (The dot shows the location of Gorakhpur) with pre-processed SAR image

\section{METHODOLOGY}

The datasets were first splitted to separate out the study area and remove any radiometric distortion. Thereafter the datasets were deburst since the data was acquired in scan or burst mode. Thereafter the data was calibrated and multilooked to generate square pixels of around $9 \mathrm{~m} \times 9 \mathrm{~m}$ size. This was followed by coregistering the datasets wherein one dataset of later date was aligned with the data of earlier date pixel by pixel. Following this, interferometric processing was carried out wherein an interferogram was generated and phase values were studied for changes if any. DEM assisted topographic phase removal and modified Goldstein phase filtering was then carried out to further flatten the interferometric phase and remove phase distortions if any. A DEM (Digital Elevation Model) map was prepared to see the low-lying areas in and around the city to correlate the water accumulation in these areas for inundation map prepared. Since closer fringes mean that more sensitive is the interferogram is to the topographic height, hence higher is the quality of DEM. For global DEM generation, SRTM (Shuttle RADAR Topography Mission) Was used in X and C bands with up to $4 \mathrm{~m}$ accuracy. Hence the DEM map was prepared by simulating the unwrapped interferometric phase with wrap ambiguity of interferogram wrapping each time to $2 \pi$ removed, over an automated plugin for SRTM. The plugin links up the interferometric fringe information with the SRTM coordinates and downloads a linked elevation information. This information generates the DEM map and georectifies the image. The DEM map showed several paleochannels of the river which got filled with water during rains resulting in bifurcation of main channels into several small channels. Lastly, areas with high backscatter were masked out from the calibrated map for both time periods and inundation maps so prepared were overlaid on Google earth. The DEM map was used to generate streamlines or flow lines to see the direction of runoff flood water. This was used to generate and calculate watershed. The watershed was used to clip out the streamlines in the area of maximum accumulation of flood water. This was further used to locate a junction of maximum submergence of agricultural area and the volume of accumulation was calculated to suggest a reservoir to be built to direct the flood water into it so as to prevent further submergence of precious agricultural land.

\section{RESULTS AND DISCUSSION}

\subsection{Pre-processing}

The datasets were pre-processed by splitting wherein each subswath was delineated and treated into a separate product to locate the 'IW' tile containing the study area (Black et al., 2017; Dwivedi, Narayan, Tiwari, Dikshit, \& Singh, 2016; Keydel, 2007). Thereafter the products are deburst since each subswath contains a series of bursts where each burst is trated as a separate SLC (Single Look Complex) product (Zhou, Chang, \& Li, 2009). Each burst includes all individually focused complex bursts into a single subswath image. Hence deburst is needed to separate out the subswath products (Sunuprapto \& Hussin, 2000). This is followed by calibration which is a useful tool since it directly relates the pixel values with the RADAR backscatter and makes the SAR imagery useful for quantitative interpretation (Shirvany, 2012). Since a SAR imagery has two directions of dimensions which are unequal- the range direction and the other azimuth direction and it has different spatial resolutions along these directions which make the image to have inherent speckle noise. To remove this ambiguity and generate square pixels, the image is multilooked (Li \& Bethel, 2008).

\subsection{Interferometric processing}

The study area was subsetted from the pre-processed images of both the time frames and was coregistered together with root mean square error of 0.02. In coregistration, the slave image usually of the later time frame is aligned pixel wise with respect to the master image of the earlier time frame (Mccormack, Thomas, \& Solomon, n.d.). This way, the changes that have taken place over the time frame are delineated and can be studied with great ease with respect to the variations in the pixel level (Chung, Liu, Cheng, Lee, \& Shieh, 2015; Keydel, 2007; Sunuprapto \& Hussin, 2000). Thereafter, an interferogram was generated from the coregistered image product, to see the changes that have occurred on the surface due to deformations if any and the change in phase that occurs as the waves return to the RADAR sensor after interaction with the target. Thereafter, terrain correction was done using SRTM DEM assisted orthorectification in which DEM map was generated.

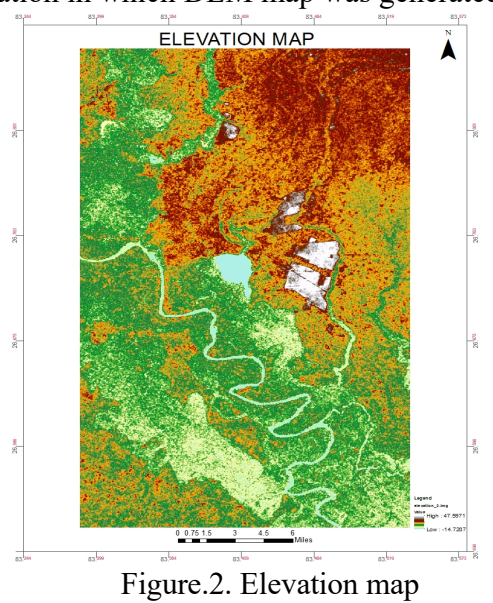

\subsection{Hydrological Processing}

The elevation map was used to generate flow lines using HECGEOHMS. These lines indicate the route that water would follow in the event of flood based on elevation differences in 
the topography of the land surface. Thereafter the catchment grid delineation was done followed by adjoint catchment processing. This created the run-off lines of flood water. After this a suitable point was taken on the major junction of drainage lines and a watershed area was delineated. The area of watershed polygon was calculated using calculate area tool. The watershed polygon was used to clip out drainage lines. The contour map generated with contour spacing $20 \mathrm{~m}$ is shown as below in Fig. 3-

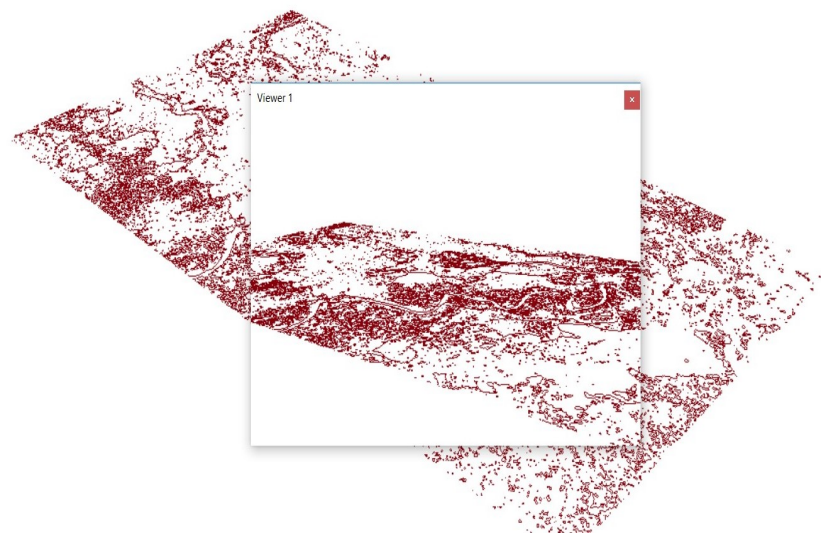

Figure. 3. Contour Map

The flow accumulation map, and Flow Direction maps, Fig.4, were also generated using the elevation map to see the direction of flow accumulation which is clearly towards low lying agricultural and urban areas and a suitable watershed area was marked.

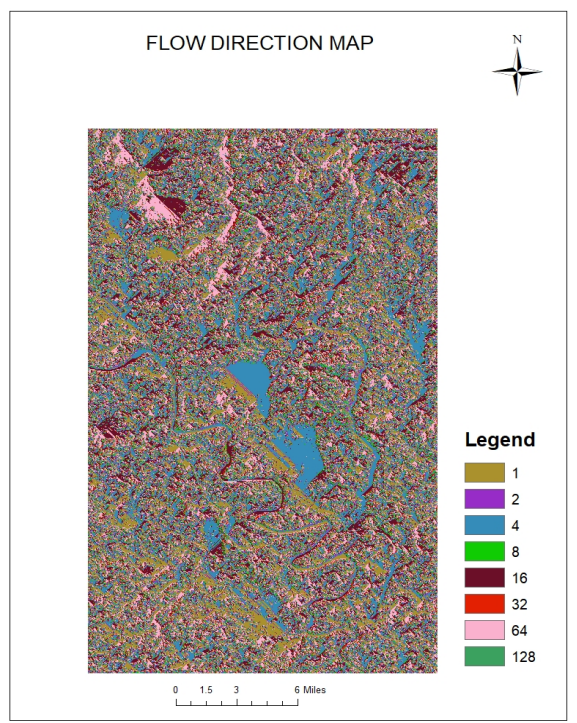

Figure.4. Flow Direction Map

The delineated watershed area map was created by selecting a junction of flow lines where the maximum agricultural area showed submergence and was calculated to be 74 sq. $\mathrm{Km}$. as shown in Fig. 5 and Fig.6-

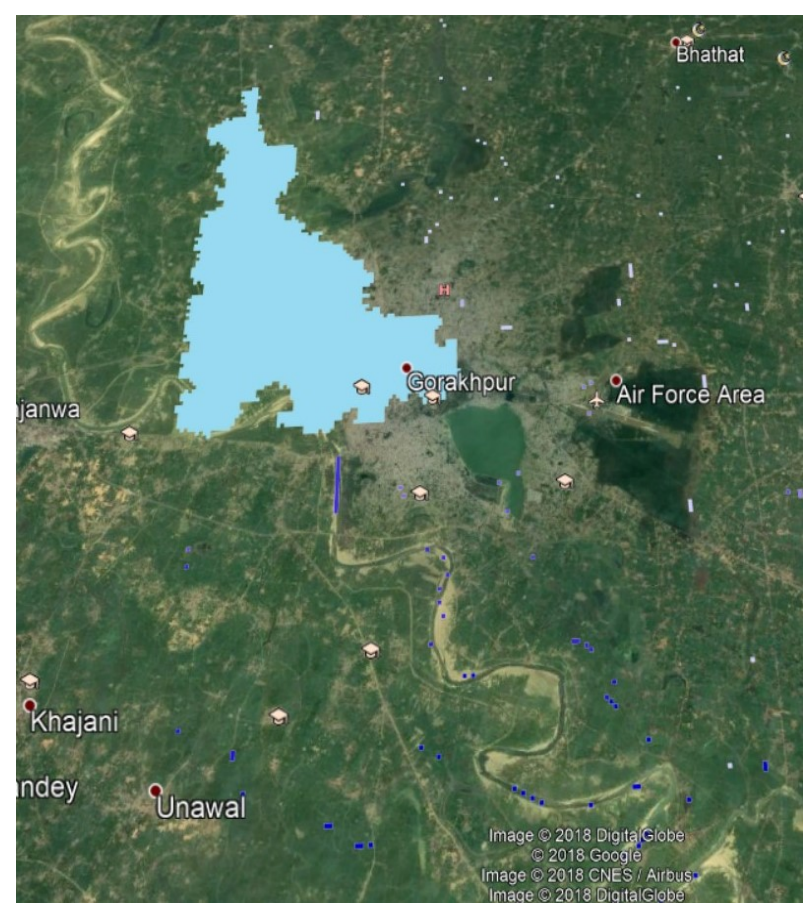

Figure.5. Watershed overlay on Google Earth WATERSHED DELINEATED

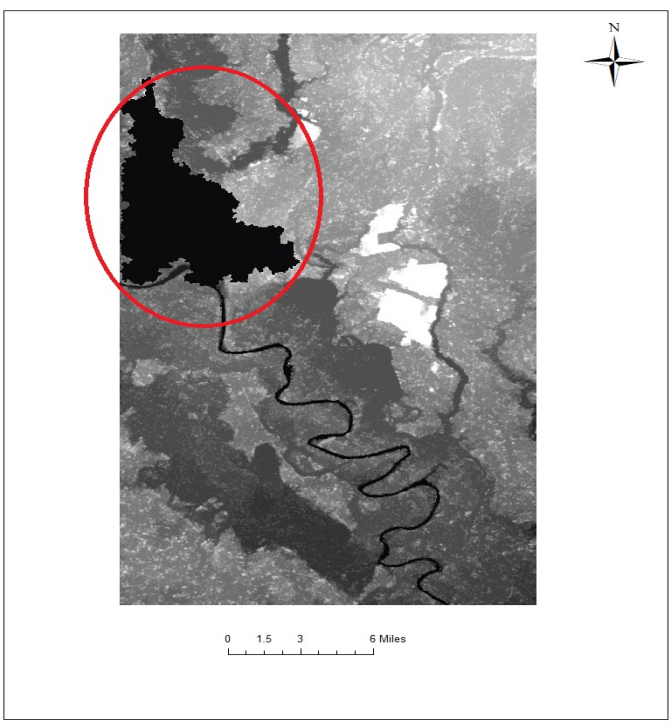

Fig.6. Watershed Map

Once the watershed area was calculated, a Triangulated Irregular Network (TIN) map was generated to find a suitable area for having a reservoir, based on flow accumulation in the watershed and calculation of volume of accumulated water. The TIN map is showed in Fig. 7.

Based on the watershed area and TIN maps, surface run-off volume was calculated over the areas where maximum damage has been done to agricultural lands. The volume came to be around 12,25,412.19 litres. Which should be the minimum capacity of the reservoir that could be built, and all the water could be diverted to it causing abatement to the land submergence in flood like situations. 


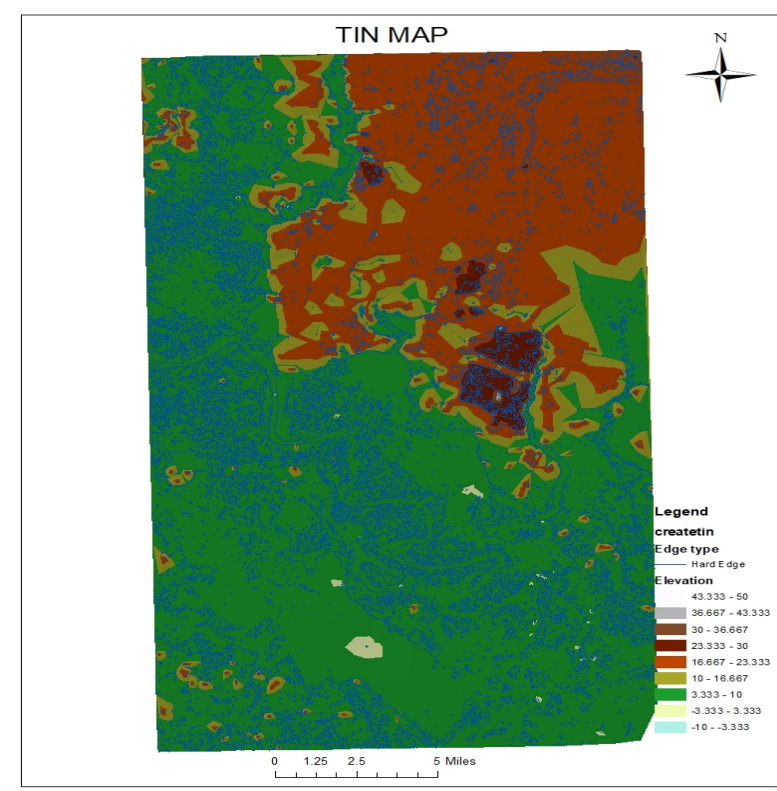

Figure.7. TIN Map showing high water accumulation over agricultural and urban low-lying areas

\section{CONCLUSION}

Spaceborne, C-band SAR data has good feasibility for flood inundation mapping as well as hydrological analysis specially for areas where flooding in the months of monsoon is a yearly phenomenon. This results into heavy loss of life and property besides submergence of agricultural land. This study aims to minimize the loss of precious agricultural land by calculating the volume of surface run-off from a watershed area so that the water could be diverted and stored for other applications into a reservoir.

\section{ACKNOWLEDGEMENTS}

This work was supported by the European Space Agency (ESA), SNAP team and IIT Ropar.

\section{REFERENCES}

Abdikan, S., Sanli, F. B., Ustuner, M., \& Calò, F. (2016). Land cover mapping using sentinel-1 SAR data. International Archives of the Photogrammetry, Remote Sensing and Spatial Information Sciences - ISPRS Archives, 41(July), 757-761. https://doi.org/10.5194/isprsarchives-XLI-B7-757-2016

Black, B. A., Perron, J. T., Hemingway, D., Bailey, E., Nimmo, F., \& Zebker, H. (2017). Planetary topography: Global drainage patterns and the origins of topographic relief on Earth, Mars, and Titan. Science, 356(6339), 727-731. https://doi.org/10.1126/science.aag0171

Chen, F., Masini, N., Liu, J., You, J., \& Lasaponara, R. (2016). Multi-frequency satellite radar imaging of cultural heritage: the case studies of the Yumen Frontier Pass and Niya ruins in the Western Regions of the Silk Road Corridor. International Journal of Digital Earth, 9(12), 1224-1241. https://doi.org/10.1080/17538947.2016.1181213

Chung, H. W., Liu, C. C., Cheng, I. F., Lee, Y. R., \& Shieh, M.
C. (2015). Rapid response to a typhoon-induced flood with an SAR-derived map of inundated areas: Case study and validation. Remote Sensing, 7(9), 11954-11973. https://doi.org/10.3390/rs70911954

Confuorto, P., Plank, S., Novellino, A., Tessitore, S., \& Ramondini, M. (2016). Implementation of DInSAR methods for the monitoring of the archaeological site of Hera Lacinia in Crotone (Southern Italy). Rendiconti Online Societa Geologica Italiana, 41, 231-234. https://doi.org/10.3301/ROL.2016.136

Dore, N., Patruno, J., Pottier, E., \& Crespi, M. (2013). New research in polarimetric sar technique for archaeological purposes using ALOS PALSAR data. Archaeological Prospection, 20(2), 79-87. https://doi.org/10.1002/arp.1446

Dwivedi, R., Narayan, A. B., Tiwari, A., Dikshit, O., \& Singh, A. K. (2016). Multi-temporal SAR Interferometry for landslide monitoring. International Archives of the Photogrammetry, Remote Sensing and Spatial Information Sciences - ISPRS Archives, 41(July), 55-58. https://doi.org/10.5194/isprsarchives-XLI-B8-55-2016

Huete, A. (2011). Land Remote Sensing and Global Environmental Change (Vol. 11). https://doi.org/10.1007/9781-4419-6749-7

Keydel, W. (2007). Normal and Differential SAR Interferometry. Radar Polarimetry and Interferometry, (October), 3-1-3-36. Retrieved from http://www.dtic.mil/cgibin/GetTRDoc?Location=U2\&amp; doc=GetTRDoc.pdf\&amp; $\mathrm{AD}=\mathrm{ADA} 470882$

Li, Z., \& Bethel, J. (2008). Image coregistration in SAR interferometry. Proc. Int. Arch. Photogramm., Remote Sens. Spatial Inf. ..., XXXVII(B1), 433-438. Retrieved from http://www.isprs.org/proceedings/XXXVII/congress/1_pdf/72.p df

Mccormack, H., Thomas, A., \& Solomon, I. (n.d.). The capabilities and limitations of satellite InSAR and terrestrial radar interferometry.

Shirvany, R. (2012). Estimation of the Degree of Polarization in Polarimetric SAR Imagery: Principles \& Applications. University of Toulouse. Retrieved from http://ethesis.inptoulouse.fr/archive/00002034/01/shirvany.pdf

Sunuprapto, H., \& Hussin, Y. A. (2000). a Comparison Between Optical and Radar Satellite Images in Detecting Burnt Tropical Forest in South Sumatra, Indonesia. International Archives of Photogrammetry and Remote Sensing, XXXIII(B7), 580-587.

Tripathi, A., \& Kumar, S. (2017). SAR interferometry based displacement mapping of cultural heritage sites. The 38th Asian Conference on Remote Sensing, ACRS 2017, Space Applications: Touching Human Lives, 1, 1-6. Retrieved from http://a-a-r-

s.org/acrs/administrator/components/com_jresearch/files/public ations/665.pdf

Zhou, X., Chang, N.-B., \& Li, S. (2009). Applications of SAR Interferometry in Earth and Environmental Science Reserch. Sensors, 9(3), 1876-1912. https://doi.org/10.3390/s90301876 